\title{
Embodied Ethical Decision-Making: A Clinical Case Study of Respect for Culturally Based Meaning Making in Mental Healthcare
}

\section{Megz Roberts ${ }^{1}$ (D)}

Accepted: 24 October 2020 / Published online: 15 January 2021

(c) The Author(s) 2021

\begin{abstract}
How does embodied ethical decision-making influence treatment in a clinical setting when cultural differences conflict? Ethical decision-making is usually a disembodied and rationalized procedure based on ethical codes (American Counseling Association, 2014; American Dance Therapy Association, 2015; American Mental Health Counseling Association, 2015) and a collective understanding of right and wrong. However, these codes and collective styles of meaning making were shaped mostly by White theorists and clinicians. These mono-cultural lenses lead to ineffective mental health treatment for persons of color. Hervey's (2007) EEDM steps encourage therapists to return to their bodies when navigating ethical dilemmas as it is an impetus for bridging cultural differences in healthcare. Hervey's (2007) nonverbal approach to Welfel's (2001) ethical decision steps was explored in a unique case that involved the ethical decision-making process of an African-American dance/movement therapy intern, while providing treatment in a westernized hospital setting to a spiritual Mexican-American patient diagnosed with PTSD and generalized anxiety disorder. This patient had formed a relationship with a spirit attached to his body that he could see, feel, and talk to, but refused to share this experience with his White identifying psychiatric nurse due to different cultural beliefs. Information gathered throughout the clinical case study by way of chronological loose and semi-structured journaling, uncovered an ethical dilemma of respect for culturally based meanings in treatment and how we identify pathology in hospital settings. The application of the EEDM steps in this article is focused on race/ethnicity and spiritual associations during mental health treatment at an outpatient hospital setting. Readers are encouraged to explore ways in which this article can influence them to apply EEDM in other forms of cultural considerations (i.e. age) and mental health facilities. The discussion section of this thesis includes a proposed model for progressing towards active multicultural diversity in mental healthcare settings by way of the three M's from the relational-cultural theory: movement towards mutuality, mutual empathy, and mutual empowerment (Hartling \& Miller, 2004).
\end{abstract}

Extended author information available on the last page of the article 
Keywords Dance/movement therapy $\cdot$ Clinical case study $\cdot$ Embodied ethical decision-making · Cultural awareness · Outpatient treatment · Active multicultural diversity model $\cdot$ Relational cultural theory

Embodied ethical decision-making (EEDM) can effectively influence treatment in a clinical setting when cultural differences conflict. Professional ethics are the standards of care and rules that govern the expectations for professionals, protect patients from harm, and guide ethical decision-making when faced with an ethical dilemma (Welfel, 2016). The two determinants of ethical decision-making are biological make-up and cultural norms (Ayala, 2010). Biological make-up includes our capacity to 1 . Anticipate consequences of actions taken; 2 . Make valuable judgments; and 3. Possess the ability to choose between courses of action (Ayala, 2010). Cultural norms are learned standards based on our shared experiences with family, friends, school systems, and other social environments (Sieck, 2019). Typically cultural norms of dominant cultures and are used to assist therapists with decision-making when faced with ethical dilemmas (Laws \& Chilton, 2013).

Ethical decision-making is usually a disembodied and rationalized procedure based on ethical codes and a collective understanding of right and wrong. Trahan and Lemberger (2014) recognized that professional ethics codes are incomplete when considering underrepresented populations. Many studies have provided examples that point to insufficient measures taken in academic settings to address cultural competency, therefore producing counselors, psychologists, doctors, and nurses who are inadequately culturally sensitive and ignore cultural complexities (Alqahtani \& Altamimi, 2015; Carmichael, 2012; Harris, 2016; Hebenstreit, 2017; Laws \& Chilton, 2013; McEldowney \& Connor, 2011; Dominguez, 2017; Wadley, 2016). The underlying somatic and intuitive constructs of our cultural norms, morals, and values are what guide our ethical decisions (Robson, Cook, Hunt \& Alred, 2000). Hervey (2007) positioned that we can enhance the ethical decision making process by shifting from a rule-based approach to an embodied approach to address dilemmas in a more effective manner.

The purpose of this clinical case study was to explore how Hervey's (2007) EEDM steps influenced ethical decision-making when cultural differences conflicted during treatment for a spiritual Mexican-American patient. My intersectional identities as an African-American, non-heterosexual woman have inspired my ambition towards creating change within healthcare systems. Healthcare systems have a long history of creating unsafe environments for people with diverse cultural identities; consequently the construct of cultural safety was established in the 1980's in an effort to protect people of color from these harmful practices (McEldowney \& Connor, 2011).

\section{Embodied Ethical Decision-Making}

As movers and body-based practitioners, it is difficult to ignore the intelligence held within the body. To explore knowledge surfacing from the body during an ethical dilemma grants vital data and, "using the body as a teacher puts the mover 
in charge of the process" (Goldman, 2004, p. 131). It further allows us to use our body for inter-affectivity and empathetic understanding (Schmidsberger \& Loffler-Stastka, 2018), thereby experiencing and sensing the perspectives of other individuals. Hervey outlined Welfel's (2001) nine ethical decision-making steps and paired them with corresponding embodiment suggestions collected from roughly 80 dance/movement therapists and student participants (Table 1). These participants attended Hervey's EEDM workshops, and from there, she analyzed the records of their movement responses and rationales to hypothesized ethical dilemmas (Hervey, 2007). I included these movement suggestions from the participants for each step in this article to provide readers with movement stimulating recommendations that may be helpful while engaging in the ethical steps as they were for me. At the time of Hervey's (2007) article, Welfel (2001) identified nine ethical decision-making steps to thoroughly guide counselors in the process of making ethical decisions. In 2012, Welfel added an extra step that includes clarifying socio-cultural contexts of the dilemma. However, since this article is embedded with cultural context, I encourage readers to consider socio-cultural contexts for their patient, the situation, and themselves throughout the entire

Table 1 Ethical model paired with EEDM steps

\begin{tabular}{|c|c|}
\hline Welfel's Ethical Decision-Making Steps & Hervey's EEDM Steps \\
\hline 1. Develop ethical sensitivity & $\begin{array}{l}\text { Notice shifts in body; Explore movement in hori- } \\
\text { zontal plane }\end{array}$ \\
\hline 2. Define the dilemma and options & $\begin{array}{l}\text { Recreate movement postures of people involved; } \\
\text { move most outrageous options }\end{array}$ \\
\hline 3. Refer to professional standards & Use of weight in vertical plane \\
\hline 4. Search out ethics scholarship & Move ethical dilemma \\
\hline 5. Apply ethical principles to the situation & $\begin{array}{l}\text { Autonomy } \\
\text { Create imaginary space \& boundaries; move in } \\
\text { vertical plane } \\
\text { Nonmaleficence } \\
\text { Careful \& cautious movement using bound flow \& } \\
\text { lightness } \\
\text { Beneficence } \\
\text { Shaping, widening, opening with horizontal plane } \\
\text { Justice } \\
\text { Balancing movements } \\
\text { Fidelity } \\
\text { Movement with weight } \\
\text { Additional: Veracity } \\
\text { Spinal movements and free flow }\end{array}$ \\
\hline $\begin{array}{l}\text { 6. Consult with supervisor and respected col- } \\
\text { leagues }\end{array}$ & $\begin{array}{l}\text { Use of verbal or movement communication to create } \\
\text { way of sharing dilemma }\end{array}$ \\
\hline 7. Deliberate and decide & Move alone; rehearse acting out plans and decisions \\
\hline $\begin{array}{l}\text { 8. Inform supervisors, implement and document } \\
\text { actions }\end{array}$ & Use of time in sagittal plane \\
\hline 9. Reflect on the experience & Reflect \& evaluate \\
\hline
\end{tabular}

Adapted from Welfel (2001) and Hervey (2007) 
ethical decision-making process, and how one's cultural lens can further deepen the movement suggestions presented by Hervey (2007).

\section{Clinical Case}

The case where the ethical dilemma arose involved a Mexican-American male patient, Juan. (Juan is a pseudonym used to protect this patient's privacy.) Juan hesitantly disclosed having a spirit attached to his right shoulder that he could regularly see, feel, and talk to. Juan was being treated in an urban outpatient hospital facility for generalized anxiety disorder and post-traumatic stress disorder (PTSD), which involved individual therapy and medication management. Neighboring communities that the hospital served were made up of majority Latino and African American identifying populations. As reported by the Chicago Community Trust (2018), social and economic resources are historically and unjustly distributed in this area, and have resulted in health inequities that nearly three times the well-being concerns of the U.S. on average.

Juan mentioned in the beginning of our work together that he did not trust hospital systems, specifically, employees who identified as White. Therefore, the patient did not disclose important information regarding his mental health to the hospital and me, as his therapist. I reflected on my own mistrust of the medical system and assured Juan that his apprehension was valid and accepted in our therapeutic space. We met once a week for two months to assist Juan with developing coping skills to manage his anxiety and to support his recovery from traumatic experiences. Our sessions included movement experientials that drew from Laban Movement Analysis (LMA) techniques, improvisational movement, and mindfulness-based activities, and were supplemented with verbal processing. Many of our sessions involved evocative verbal exploration into Juan's interpretation of his life experiences; this helped to strengthen our therapeutic relationship and build trust. During our seventh individual session, one of his deepest secrets was revealed. He stared me in the eyes and stated, "I have a spirit attached to my right shoulder. I can see him and feel him. He's talking to you. Can you hear him?" I was thunderstruck and became curious about his unexpected disclosure. The spirit had attached to Juan two months prior after he prayed to his God for companionship and guidance. What started out as a positive human-spirit friendship turned into daily negative comments from the spirit, which led the patient to share his experience with me, but not without hesitation.

Juan communicated that he would not return to treatment if the divulgence of his private information had to be revealed as he had his own codes that he lived by. Identified as street codes, or rules regulating interpersonal public behavior (Anderson, 1994), these rules evolved from street culture as an adaptation to the lack of faith and trust in America's oppressive systems. Street codes recognize that toughness is a virtue and that vulnerability equaled death; thus, privacy is a necessary survival skill amongst cultures that are dependent upon street living (Anderson, 1994). 
Additionally, Juan closely identified with being spiritually gifted since childhood. He talked about seeing people's auras (even mine) and sightings of spiritual entities throughout his upbringing and adulthood. This was the first time Juan had confided in anyone, aside from his mother, about seeing spirits.

\section{Culture Interfaces in Ethical Decision Making}

Spirituality, religion, and culture have been omitted from psychology for many decades. Current mental health models are built upon, and view patients through, a mono-cultural lens (Dominguez, 2017) and this miscommunication results in increased and worsened health disparities for populations who identify as nonWhite. Ethical decisions become harmful when they disempower the cultural identity of a patient and insensitively discount individual and cultural views of treatment (McEldowney \& Connor, 2011). Although my dance/movement therapy program often brought awareness to culture, I still did not feel prepared or adequately trained to know what to do with Juan's disclosure.

While the support and involvement of practitioners who identify as persons of color are insufficient, there are new efforts being made to reduce these deficits in mental health programs (Dominguez, 2017; Walker, Burman \& Gowrisunkur, 2002). For example, Frame and Williams (2005) introduced an ethical decisionmaking model from a multicultural perspective that helps therapists view differently the Eurocentric, one-dimensional, and ruled-based way of approaching ethics. The counseling profession has begun to support the idea of spiritual needs in counseling for patients and has shown an increase in therapy effectiveness, both spiritually and psychologically (Giordano \& Cashwell, 2014).

\section{Theoretical Orientation}

Informed by a humanistic/existential paradigm and a relational-cultural theory (RCT) and positive psychology clinical approach, my spirituality, intersectional identities, and familial experiences motivated me to fully engage in this clinical case study and to advocate for increased multicultural competency amongst healthcare practitioners. From a relational-cultural perspective, our goal when Juan and I worked together was to build our relationship, so as to increase the patient's sense of safety and trust within the treatment facility and me. My positive psychology approach served to foster the patient's happiness and well-being in addressing his adverse life experiences. Both approaches led to a strong therapeutic relationship between Juan and me, and helped to increase his ability to open up and share with me his circumstance with the spirit. 


\section{Exploration of Ethical Decision-Making with Juan}

It was clear that further culturally based ethical decisions needed to be made in order to provide ethical, safe and cultural focused care to Juan. This article identifies and evaluates the EEDM process by working through the case using the embodied ethical steps as outlined by Hervey (2007). Along with the movement recommendations from Hervey (2007), I also explored my own movement experiences as I embodied each step in response to my ethical dilemma during the process of writing this article.

\section{Step One: Become Familiar}

Given how violently ethical conflicts can be experienced in the body, (Hervey, 2007), clinicians are drawn away from their embodied experience and shift towards more cognitive approaches to solve ethical dilemmas. Instead of allowing this mind/ body disconnect to happen, dance/movement therapists are able to embrace the body using EEDM steps. Hervey (2007) reminds readers that true ethics started as a bodybased experience of wrong and right, and in order to find appropriate solutions for ethical dilemmas, one must return to the body for guidance. Embodiment permits us to move past the rational thinking brain (prefrontal cortex) and enter the body. This allows us to develop ethical sensitivity and recognize that there is an ethical dilemma in existence (Hervey, 2007). Step one involves attending to our body's experience (Csrodas, 1993) by being present and engaged with its perceptual experience. This takes place in the form of movement.

Analytic and somatic movements are two avenues to consider when analyzing bodily movements (Moore, 2014). Moore (2014) introduces analytics as the observation of body movement from an external perspective and somatics as the firstperson perspective of internal movement. Csordas (1993) adds that the somatic dimension of movement not only includes attending to one's internal bodily experiences but also involves attending to the bodies of others, called the somatic modes of attention. Humans are gifted with the ability to interpersonally connect in a way that allows us to feel what others feel when we exercise our use of mirror neurons. Analytic and somatic movement shifts from one's self and their environment provide evidence that deepens the collection of information and tell us when we have an ethical dilemma on our hands. Again, in this first step of EEDM, it is suggested to postpone any type of action, only to recognize the existence of an ethical dilemma in order to prevent premature and inappropriate action (Hervey, 2007). Instead, Hervey (2007) positions that "vertical containment" of just attending to the body signals and exploring movement in the horizontal plane is ideal for the initial development of an ethical dilemma.

\section{Embodiment of Step One}

In the initial stage of the ethical dilemma presented in this article, my movements became accelerated in the sagittal plane, specifically in my upper limbs, torso, and 
core. There was a sense of urgency I felt to confide in someone about Juan's release of private information regarding the spirit attached to his shoulder. I was fascinated by my in-session encounter and wrote in my journals about feelings of excitement and tingling surges running through my body. I also recorded my impression of shaky sensations in my arms, knots in my throat and core, and decreasing pressure in my lower body. Tortora (2006) explains that weight assumes the physical intention of executing an action; the decreasing pressure I experienced in my legs indicated how careful I was to move forward in the dilemma. The vibratory action in my arms implied feelings of anxiousness, and the knots in my throat and core signified some sort of blockage. In my journal I reported feeling a sense of imprisonment; my body felt the restraint of navigating such a cultural dilemma in a hospital setting embedded with Eurocentric forms of healthcare. Though I was excited to learn more about Juan's experience with the spirit, my movement observations for my core, arms, and legs suggested and confirmed a hesitancy to approach and navigate the disclosure about the spirit. I was motivated and empowered to advocate for him, but I also felt sad and angered by my thoughts of foreseeable outcomes that would be adverse to our therapeutic relationship. Given the cultural context of the dilemma and its tendency to be overlooked in westernized hospital settings, my thoughts held weight. I avoided making any decisions to address Juan's case, except to obtain support in supervision.

\section{Step Two: Define the Dilemma}

After identifying that an ethical dilemma exists, we are encouraged to define the dilemma and identify potential problem solving opportunities. For this case, the ethical dilemma was respect for culturally based meanings in treatment and how mental health clinicians identify pathology. Juan believed his seeing the spirit was a gift given to him by God; he refused to accept any diagnosis that labeled it otherwise. What Juan described as a spiritual experience is usually understood as a form of psychosis in hospital systems that rely on symptom identification and diagnosis for the treatment of symptoms. Despite encouragement from me, he opposed the idea of talking to his psychiatric nurse about his spiritual experience. I felt stalled between my own spiritual and cultural awareness, Juan's spirituality, his safety, and having to uphold the policies and procedures of the hospital where I was interning. I understood Juan's story as a spiritual person, as a clinician, and as a Black woman from the inner city of Chicago; but I wondered if I resonated with his story all too well because we shared the people of color in the American healthcare system narrative. I wanted to make sure he felt heard and included in his treatment. On the other hand, I wanted to avoid compromising his safety in an effort to advocate for him and for increasing cultural awareness at my site. This case with Juan was a culturally embedded ethical dilemma that required my full participation with the embodied ethical steps. 


\section{Embodiment of Step Two}

My body and my mind felt uneasy about making a decision; there was a fight between my cultural background and my emergence as a clinician. The idea of both weighed heavy on my shoulders and drained my energy. My upper torso gradually sank downward along the vertical dimension and my entire body wanted to enclose itself and curl like a ball. I encountered feelings of isolation as one of few Black clinicians at my internship site as well as in the academic program at my college. I felt lonely in my ethical dilemma. There are very few articles that talk about a Black clinician's experience of loneliness during a culturally situated ethical dilemma. Smith (2012), communicated in her thesis about a similar struggle she felt during an ethical dilemma when battling between holding on to her cultural identity as an African American woman versus choosing an identity as a clinician and abiding by ethical codes. I thought with frustration: Why does there have to be a choice? Why cannot my cultural background and my developing identity as a clinician co-exist? Hervey (2007) acknowledged the need to cope with one's bodily felt experiences when managing complex cases. She concluded that dance/movement therapist found value in moving out the dilemma with full embodiment to support determining the next direction to take. In my attempt to release my body from the enclosed ball and fully embody the dilemma, I encountered hesitation and emotional discomfort. I felt my anger and frustration expand with my movement in the form of increased pressure and restricted affect. My body was reluctant to engage in an emotionally overwhelming, cultural dilemma, but there was a sense of freedom in knowing that I was not giving up.

Step two further required the embodiment of my patient as well as my supervisors and the treatment team to provide an empathic approach to decision-making and deciding the best course of action. In her workshops, Hervey (2007) noted that in this step participants commonly collaborated with one another using creative movement to unlock alternatives to ethical dilemmas. I recall deliberating about the advice of my supervisors, unsure if they realized the substance of my patient's fear and request for confidentiality given that they did not identify as people of color. For them, it appeared simple: make sure he's not homicidal or suicidal and inform the nurse practitioner. Juan denied suicidal (SI) and homicidal ideation (HI). But again, one of my supervisors informed me that regardless of his denial of SI and HI, it was imperative that I report his spiritual experience to his nurse due to the fact that she prescribed him medication and that operating as a team in our department was a requirement.

Embodying Juan, my supervisors, and others who played part in the dilemma, such as the psychiatric nurse, helped to increase my understanding of their positioning in the case. My movement consisted of taking on each person's postures and gestures, and verbalizing notable statements from our encounters. My kinesthetic empathy allowed me to view the case from their perspective. I felt each person's concern for safety: safety for the patient, the hospital, the college, and each person involved in the dilemma, including myself. To consider safety for everyone and everything taking part in the ethical dilemma, it required diverse methods of examination, risk 
management, and knowledge. My movement responded with openness to the varying perspectives of stakeholders.

\section{Identifying the Options}

Lastly in step two, Hervey found it helpful to encourage participants to imagine the most ludicrous option and move it (Hervey, 2007, p. 103). In this way, options disregarded due to fear and being premeditated as unethical decisions become spontaneous possibilities to solving one's ethical dilemma (Hervey, 2007). Identifying options will help counselors focus their energy during complex ethical dilemmas. In Table 2, I present options considered for Juan's case. Ultimately, I wanted to avoid causing harm to him and his beliefs by providing space for autonomy and cultural advocacy. Conversely, I was thoughtful about improperly treating a patient who may in fact benefit from receiving a diagnosis in alignment with his symptoms.

\section{Step Three and Four: Search, Evaluate, and Determine}

Hervey (2007) joins steps three and four of Welfel's (2001) ethical decision-making model into one complete phase to evaluate options and to determine the best solution. It requires dance/movement therapists to utilize professional literature, ethical codes and regulations, and agency policies to provide structure for later deliberating processes (Hervey, 2007). Referencing codes, regulations and policies, as implied by Constable, Kreider, Smith \& Taylor (2011), helps novice therapists navigate the uncertainties associated with ethical decision-making. Even for experienced counselors, this step remains a priority for continued growth and development and enhanced ethical judgment (Oramas, 2017). Ethical standards are designed to protect professionals and patients; yet, these standards usually result in more reactive than proactive ethical decision-making (Trahan \& Lemberger, 2014). So in addition, seeking guidance from ethics scholarship enables

Table 2 Options Considered for Juan's Case

\section{Possible options considered}

1 Disclose to the treatment team that Juan is experiencing psychosis as evidenced by visual and auditory hallucinations in the form of a spirit

2 Postpone making a decision while extracting more details from Juan about his culturally based understanding of the spirit

3 Consult with supervisor about possible solutions

4 Consult with other respected and more experienced clinicians

5 Advocate as a dance/movement therapist for culturally based meaning making in treatment and defend Juan against westernized systemic norms

6 Disregard that Juan brought up the spirit and do nothing

7 Most Outrageous: Provide undeniable evidence the spirit is real 
counselors to vicariously learn by trial and error from practiced professionals. Aside from providing clarity, focus, and structure, this step also increases confidence through skill building and acquisition of ethical knowledge, and further limits risky decision-making. Once all relevant information has been obtained regarding options identified in step two, dance/movement therapists are to move out those possibilities. It is essential to utilize this step as an explorative measure with movement to create more available options than to rely on rules to quickly resolve the dilemma (Hervey, 2007).

\section{Codes and Scholarship}

The ethical dilemma of respect for culturally based meanings in treatment and how mental health clinicians identify pathology is related to the American Dance Therapy Association's (ADTA, 2015) ethical standard of display of integrity within the therapeutic relationship. It states, "Dance/movement therapists encourage the patient's voice in treatment and respect the patient's right to make decisions based on personal values" (ADTA, 2015, p. 3). The ADTA (2015) Code of Ethics additionally encourages dance/movement therapists to continuously reexamine their own biases and worldviews to avoid imposing them onto patients, and to consider the impact of oppressive systems on individual patient experiences. According to these ethical codes, Juan had every right to name his spiritual experience as he saw most fitting with his beliefs. Providing space for Juan to do that directly aligned with my obligations as an intern dance/movement therapist. However, the hospital did not ascribe to these standards. Though Juan experienced a sense of safety in my office space, we were a part of a larger operating system that he relied on for treatment.

The American Counseling Association's (ACA, 2014) ethical code Avoiding Harm and Imposing Values states that counselors work to avoid harm and minimize potential harm to patients. I perceived there could be potential harm in revealing Juan's undisclosed information to the treatment team. Counselors are trusted with the safety of each patient as they enter our therapeutic spaces, and as humans who have accepted the responsibilities of a counselor as a life calling, we feel competent enough to complete this task. Avoiding harm requires more than providing evidencebased interventions, private and clean spaces for therapy, judgment-free zones, and upholding ethical standards. It requires constant self-awareness and reflection, and honoring cultural differences.

The ADTA (2015) Codes of Ethics are informed by and parallel the ACA (2014) Code of Ethics. It is acknowledged that the ACA Code of Ethics was constructed and shaped by an individualistic, Western society (Birrell \& Bruns, 2016) and remains firmly established in a modern society that accordingly places emphasis on rules, independence, and power-over rather than relational engagement and power-with patients in treatment. Ergo, complex situations in treatment settings become central when persons in power are compelled to make ethical decisions regarding the wellbeing of a patient, even when cultural beliefs conflict (Laws \& Chilton, 2013). The patient in this case had a different cultural meaning of issues regarding his psyche than that of the hospital setting where he received treatment. 
The Diagnostic and Statistical Manual (DSM) of the American Psychiatric Association (APA) is a manual of classified mental disorders that serves as a guide for interventions and treatment recommendations. In the DSM-5 (APA, 2013), a practical diagnosis for Juan's case would fall under schizophrenia spectrum and psychotic disorders given his presentation of what the mental health field considers visual, auditory, and somatic hallucinations. Overtime, the DSM-5 has integrated cultural factors into disorders in the form of V-codes, described as supplementary conditions influencing a disorder. V-code 62.89, "Religious or Spiritual Problem", accounts for loss or questioning of religion or spirituality (APA, 2013, p. 725), however, this code does not encompass religious or spiritual factors as it pertains to this case. The option of diagnosing Juan carried the risk of deterring him from seeking therapy and decreasing his overall well-being. A diagnosis would suggest that his cultural interpretation of his spiritual experience was either false or meaningless. Timimi (2014) and Allmon (2013) are clear that these types of interpretations of culturally based beliefs disempower the patient and could increase negative symptoms.

The second professional value listed in the ACA's (2014) code of ethics honors and supports, "the worth, dignity, potential, and uniqueness of people within their social and cultural contexts" (p. 3). Since values are the cornerstone of which ethical decisions are carried out, counselors are to refrain from submitting a diagnosis if they know that it will cause harm to the patient in some way (ACA, 2014). It is rational to consider how the stigmatization of an oppressive label from the western culture will cause individual, cultural, and societal adverse consequences for some patients (Ratts \& Hutchins, 2009).

Social consequences for the patient must be taken into consideration when making ethical decisions (Zheng, Gray, Zhu \& Jiang, 2014). Usually in the decisionmaking process, the counselor identifies the ethical dilemma, takes the necessary steps to problem-solve outside of the therapy room, and decides on a resolution to the dilemma absent the patient's voice (Birrell \& Bruns, 2016). Yet, the ACA's (2014) code of ethics states that counselors work collaboratively with patients to promote growth and development during an ethical decision-making process. Shared decision-making (SDM) is a model that was first developed in the 1980's to improve the experience of patients in treatment settings by encouraging a collaborative process between the patient and health professional (Bradley \& Green, 2018). This comes with controversy regarding the risks of granting access to a patient, which allows them to collaborate with doctors regarding their treatment, given their level of competency of medical knowledge may be limited (Christine \& Kaldjian, 2013; Herlitz, Munthe, Torner \& Forsander, 2016). The same is true to consider when patients are invited to autonomously collaborate in counseling settings.

\section{Embodiment of Steps Three and Four}

As I embodied the Effort weight, for this ethical dilemma, I found strong feelings surfacing about my cultural identity and the desire to advocate for marginalized groups. There was increasing pressure in my upper body and I associated this with the idea of fighting oppressive systems at my site, as well as healthcare systems in general. I let that increasing pressure sink downward into my lower body and invited 
decreasing pressure to my upper body. The anger and frustration of having to engage with such a system did not disappear, however, awareness of my embodied experience encouraged me to take a gentler approach to ethical decision-making.

I had a lot mixed feelings that were reflected in my movement while searching the ethics codes and gathering information. I felt confused and surrounded by information as I turned in circles reaching and pulling. The information seemed full of loose ends and, to a great extent, required interpretation. There was increased tension in my shoulders, and I eventually distanced myself from the imaginary visual of the ethics codes and scholarship. I entered into a remote state of increased bound flow and directing as I gazed at the information from a far. I began to move in my preferred style of popping and locking while visualizing the information regarding the clinical case. I was able to bring in my culture when understanding and interpreting the codes. Although complete clarity of the codes was not realized, I experienced increased confidence and intention for working through the dilemma with this new knowledge.

\section{Step Five: Ethical Principles}

Step five requires reference to the five ethical principles identified by Kitchener (1984). They are: autonomy, nonmaleficence, beneficence, justice, and fidelity, along with the added principle: veracity. Ethics involves cultural norms, personal morals, and values during the decision-making process, and these will serve counselors in the self-exploration process of relating to the guiding principles (Evans et al., 2012). Ethical principles were conceptualized to provide a foundation of morals to help interpret ethical codes and adjust routine responses to unconventional ethical dilemmas (Chmielewski, 2004).

Each ethical principle has been layed out with common movement qualities that were found by dance/movement therapists when they moved out the principles separately (Table 1; Hervey, 2007). A key part of step five is to be attentive to any embodied responses that are experienced while moving each principle. Principles have the potential to draw out essential details to help us strengthen our understanding of the dilemma and where the conflict is coming from, externally, and internally within ourselves in the form of values (Miller \& Davis, 2016).

Another key factor is to acknowledge that these principles were created as a guide to culture-specific standards of behavior, and that ethical principles will be prioritized differently within varying cultures (Gauthier, Pettifor, \& Ferrero, 2010). The new age invites new rules of behaviors, and these rules are changing rapidly (Hoose, 1986). It is important to be aware of the cultural body's response to each principle and how it shapes our experience with them.

\section{Autonomy}

Autonomy describes mutual respect in a relationship, where both individuals honor one another's ability to make autonomous decisions (Kitchener, 1984). During complex ethical dilemmas, counselors may feel an urgency to act on impulses, yet feel 
the tension of respecting the autonomy of the patients, others involved, and that of themselves (Hervey, 2007). Indeed, the act of yielding and pushing through movement, which can be realized in dance/movement therapy, informs our boundaries and asserts greater independence (Schwartz, 2018).

There was constant pushing in my movement to create boundaries while embodying autonomy. I used my arms to separate and push back on the healthcare system to provide space for Juan and myself. It felt like I was taking on the role of advocate: working to gain autonomy for two people of color in a Eurocentric hospital setting. While moving I wondered how much autonomy could I actually encourage Juan to have given his presentation of symptoms and possible limitations of mental health information. Juan had previously omitted important details regarding his symptoms because he did not feel safe. I cautioned myself against allowing too much space as I thought about what other information might be unknown about him. As I moved and created space for myself, I realized I needed separation from both Juan and my internship site to be free in my own autonomy. In a cultural sense, autonomy for me meant expressing and standing strong with my own beliefs. I had responsibilities as an intern clinician to uphold the policies at the hospital, policies that I understood to be Eurocentric cultural norms and did not fully agree with. However, as a novice clinician, how much autonomy could I possess given my own limitation concerning the knowledge of policies and procedures regarding the clinical case? I engaged in a back and forth movement, suggesting the tug between inviting space for autonomy and enclosing space where autonomy may have been less beneficial to resolving the dilemma.

\section{Nonmaleficence}

Nonmaleficence means not causing harm to patients, including intentional actions to harm or carrying out risky actions that have the potential to harm them (Kitchener, 1984). This ethical principle corresponded with careful, cautious, and tentative movement responses (Hervey, 2007).

I attuned to my visceral experience of decreasing pressure and binding flow, as suggested by Hervey (2007), as I moved carefully. There were multiple pieces to consider to avoid harm. I wanted to culturally empower Juan and I wanted to keep him safe; however, safety could have looked like many things from the different perspectives of everyone involved in the dilemma. Safety could look like Juan feeling empowered and gaining trust in the healthcare system because he felt heard and believed by his treatment team. Safety could look like diagnosing Juan and giving him medication from the nurse's perspective. Safety could look like informing Juan's treatment team and engaging in ongoing investigation of his symptoms from my supervisors' perspective. Safety could also look like keeping the information to myself and linking Juan to spiritual healers in nearby communities. I engaged in movements that looked like dipping and dodging as I moved, carefully considering all of these pieces that surfaced. I further examined my own safety in relationship to nonmaleficence. A decision to inform Juan's treatment team would potentially cause harm to my cultural identity; I would feel like I betrayed my values and 
my community by going against street codes and abiding by rules of a mistrusted healthcare system. On the other hand, a decision to not inform the treatment team would leave me feeling disconnected as a team member at the hospital and also feeling like I am not doing my job correctly as a clinician; both would cause harm to my professional identity.

\section{Beneficence}

Beneficence is the act of reducing human suffering by supporting the welfare of others and enhancing their sense of empowerment (Jennings et al, 2005). This was a principle that I found myself sitting on during the time of my ethical dilemma. There is a two-sided impression of what doing good actually looks like; it could be the literal act of taking action to do good, or it could involve being good in a time of complexity and chaos (Hervey, 2007). Naturally I wanted to advocate for Juan by taking action, and I deemed it necessary for a culturally embedded case. Robson et al., (2000) argues that beneficence carries the obligation for counselors to seek substantial knowledge and perform in the best interest of the patient's welfare. On the other hand, I felt that beneficence was just being good for my patient by offering a therapeutic space where his cultural interpretation of his experience was true, regardless whether the site was willing to change its process of labeling pathology. My upper torso instantly advanced forward in the sagittal plane without hesitation, my head shook side to side suggesting the word no, my limbs supported me with increased weight. My body gladly considered no other option but to actively engage in this clinical case by advocating for Juan and other underserved people who could benefit from a change in the healthcare system.

\section{Justice}

Justice, as an ethical principle, means fairness, treating others as equals, and promoting equality counseling. This ethical principle was most challenging for me to embody. In my body I felt stuck with increased bound flow at thoughts of how inequalities in healthcare systems continue to persist. In my exploration of balancing movements for justice, my body maintained its bound flow in every part except my arms. My bound flow was accompanied by rage and sadness. I attempted to take on the posture of the scales of justice with my hands held outward to the side; they felt empty and light. I brought my hands in front of me, side-by-side, and gazed at the emptiness for a moment. The ethical codes themselves require revamping to address the inequalities that exist within them (Kitchener, 1984; Robson, et al., 2000; Trahan \& Lemberger, 2013). 'It started to become clear that Juan's case was a step forward in advocating for others like him who want and deserve fair and culturally sensitive treatment. This clinical case study was a component of seeking justice in itself.

\section{Fidelity}

Fidelity is an act of faithfulness; it is about remaining loyal and keeping promises to patients (Kitchener, 1986). This was another challenging principle to embody. The 
moment a counseling relationship is established, there is an obligation on the part of the therapist to honor commitments and promises, and to fulfill the responsibility of trust and accountability (Wade, 2015). While some dance/movement therapists affiliated fidelity with commitment, honesty, and integrity, others associated it with retaining secrets. I considered how this principle could relate to one of my options: doing nothing and disregarding my patient's spiritual experience in an effort to protect Juan from harm. During my embodied experience, I felt the sensation of being pulled in different directions with an uncomfortable tingling sensation in my stomach. I was confounded, caught in the middle of both my developed and emerging identities. On one end, I felt a pull from my patient to be with him in our marginalized identities. On another end, I felt pulling from my internship site and the counseling field to be an ethical therapist. Lastly, I saw an image of me pulling myself to just be me and to separate from both. I resorted back to autonomy and engaged in boundary setting movements, realizing that being faithful and honest to myself was my first responsibility.

Healthy disconnections are a key factor in the RCT framework. I refused the idea of becoming enmeshed with either the hospital or my patient during process of navigating the dilemma. I desired a healthy balance of connecting and disconnecting, which meant standing in my own identity while engaging with the clinical case. I reflected back to autonomy while moving this dilemma; fidelity helped me see where multiple truths encountered and overlapped one another. The nurse practitioner's truth may be helping others in an informed way by assigning diagnostic labels in order to effectively treat multiple patients and prescribe medication. The nurse's truth overlapped Juan's truth of seeing his mental concerns as something spiritual, but not having many resources to turn to for support. I understood fidelity as a principle to encourage all involved in the case to be true to themselves and not place rules and labels above being human.

\section{Veracity}

Veracity was added to the most recent addition of the ACA's (2014) Code of Ethics and is defined as dealing truthfully with individuals during professional interactions. In my embodiment of veracity, I discovered a vertical stance that turned into spiraling movements of my spine with free flow and lightness. I felt authentic and vulnerable in my movement, and I also felt the willingness to share myself and connect with others involved in the ethical dilemma. True veracity requires authenticity to be effective; vulnerability is a bonus. It goes back to fidelity and being aware of placing rules above respect for human differences. The dilemma in this clinical case rose from a lack of acknowledgement of cultural differences and viewing ethical dilemmas through intellectualized codes instead of the truth within the human body.

\section{Step Six: Consult and Share}

When does spirituality become pathology? How do we ethically honor a patient's cultural meaning of spirituality in a westernized medical system? These were 
the questions that had surfaced for me in supervision. Interestingly, I had three White identifying supervisors, and I was one of very few Black clinicians in training at my academic setting and the only Black supervisee at my site. There is an established power differential that comes with a supervisee-supervisor relationship which was compounded by Black-White dyads that constituted each of my supervisory relationships. Clinicians of color in training commonly experience their voices being silenced in clinical and academic settings, especially when topics of culture and race need to be addressed (Estrada, 2005; Hardy, 2015; Hernández, 2003; Jernigan, Green, Helms, \& Perez-Gualdron, 2016). This is likely a consequence of practiced cultural conditioning in Western societies as well as a lack of cultural awareness and training that has persisted throughout the counseling field, thus continuing the cycle of supervisors overlooking cultural issues (Estrada, 2005; Vereen, Hill, \& McNeal, 2008; Jernigan, et al., 2016; Ivers, Rogers, Borders, \& Turner, 2017). As a result of being a therapist in training, a therapist of color, and dealing with an ethical dilemma involving a cultural conflict, I was very hesitant to confide in my supervisors due to our cultural differences.

I struggled with feelings of discomfort when it came time to discuss the dilemma with my supervisors. Supervision felt like an unsafe setting to express my anger and frustrations of being a Black woman working to resolve an ethical situation deeply embedded with cultural conflict. My experience was not normalized. When I brought up the cultural factors of the case, the room seemed to either become silently heavy or the conversation deflected to an idea outside of culture. That only led to more frustration. I wanted to avoid the angry Black woman stereotype that accompanied my skin tone and aesthetic appearance and affected the way others perceived me interpersonally. I knew it would only hurt my professional career if my expressions were perceived outside of professional behavior, whatever professional behavior is according to Eurocentric standards. Consequently, I eventually suppressed my feelings and operated from a place of numbness whenever I had to discuss the clinical case further. I thought it was pointless to continue to take my body through a wave of unheard, misunderstood emotions. Suppressing my feelings and emotions was not the best coping strategy, but it was healthier and less exhausting than continuing to feel shut down or deflected. I objectively shared all the facts about the case with Juan. I did not share my subjective experiences, at least not nearly to the extent of how they lived in my body during supervision.

\section{Embodiment of Step Six}

Hervey (2007) recommends that dance/movement therapists share their ethical dilemma with trusted colleagues or supervisors through authentic movement, verbal communication, or by designing their own way of sharing. Step six aims to increase the mover's confidence for consultation.

While engaging in this step during my journey of writing this article, I experienced step six to be helpful with extracting the dilemma from my body and putting into movement. I shared the dilemma alone first, and then I shared my 
movement with a peer. By first moving the dilemma alone, I was able to see what I wanted to share and how I wanted to share it, absent the influence of another body in the room. When I offered my movement to my confidant, I was again nervous, worried about their criticism of my choice of movement, as they were unfamiliar with embodiment practices. The art of moving past internal and external criticism of who I am as a dance/movement therapist allowed me to connect deeper to how the dilemma lived in my body. I could extract it and put it into an art form in which I have always experienced healing. It allowed me to gain control over what was suppressed inside of my Black body.

\section{Step Seven and Eight: Deliberate, Decide, and Rehearse}

Steps seven and eight of Welfel's (2001) ethical model prompt therapists to deliberate and decide the best plan of action, and Hervey (2007) puts emphasis on taking responsibility of the final decision. Ethical thinking is a complicated process and we must consider the impact of our decisions on individuals and the institution we serve (Chmielewski, 2004). Without careful acknowledgement of the responsibility we hold in these types of situations, counselors run the risk of creating unsafe environments for current and future patients, and further risk producing adverse consequences for institutions. (Chmielewski, 2004). This step precedes any action to promote clarifying our intentions while solidifying our final decision.

\section{Decision Made for the Case with Juan}

I decided to inform Juan's nurse practitioner of his spiritual experiences. Ultimately, it felt like I was without much choice as I had already informed my internship site supervisor before I was aware this clinical case was an ethical dilemma, and one that would affect me deeply from a cultural perspective. I abided by the rules of the hospital and complied with directions given to me regarding the next steps to take. Before disclosing Juan's information, I talked with him in one of our sessions about my obligation as an interning clinician to inform his nurse. Again, I provided the option for him to tell his nurse, alone or accompanied by me; however he refused both. Juan stated he understood and respected my responsibilities, but he would not return to therapy. I informed him of the sadness that his decision brought me and expressed that I also understood his responsibility to protect himself. In the end, Juan ended up coming back to therapy. The relationship we built in our therapeutic space of allowing our cultural identities to exist freely without judgment surmounted the undesired ethical decision that was executed, and led to Juan's return.

Honestly, if I could go back and engage in this ethical decision-making process and change something, I would not. The process has taught me so much about who I am as a clinician and an advocate of cultural needs in healthcare systems. I also believe that Juan benefitted greatly from our therapeutic relationship that involved increased sensitivity to and active inclusion of cultural differences. Though he felt our trust was broken, we were able to rebuild it in our proceeding sessions by repairing the rupture that had taken place. Repairing our rupture contributed to 
strengthening our therapeutic alliance even further. From an RCT perspective, the therapeutic relationship was the healing factor to the decision made in this culturally situated ethical dilemma.

\section{Embodiment of Steps Seven and Eight}

In order to clarify intentions and solidify a plan, dance/movement therapists are directed to move alone, journal, or do both while deliberating (Hervey, 2007). This is a resourceful point in the ethical decision-making process to connect all of the important pieces of the case and evaluate the risks involved for one's self, the patient, and treatment team. The deliberation process can create feelings of reconnection and groundedness as we reach for clarity. Once deliberation has been finalized and intention clarified, the next measure is to commit to a plan of action (Hervey, 2007). It is recommended to rehearse acting out the final decision through movement or imagination to increase one's confidence before implementing the plan (Hervey, 2007). After the decision has been carried out, counselors are to head into the final step of the EEDM process for reflection. In an effort to support a reconnection to my own intentions, it was helpful for me to ask myself questions as a way to facilitate my movement. For instance: What motivated me to engage in this ethical decision-making process? Why and how will this benefit my patient? How will my decision support future patients and therapists who encounter a similar ethical dilemma? It was interesting to notice my arms reaching outward in all directions of the dimensional scale, and then carving their way back to my core, as if they were bringing me something back. I experienced a sense of clarity, and moreover, I experienced a sense of knowing who I am in this dilemma, and on a spiritual plane, what purpose this dilemma has brought to my career as a dance/movement therapist.

\section{Step Nine: Reflect and Evaluate}

Though Hervey (2007) excluded this final step from her workshops, it is important to engage in this reflective step to evaluate how effective the entire EEDM process has been, and doing so in an embodied fashion (Hervey, 2007). While understanding what parts of the process were effective, it is also possible to learn what steps can be done differently for future dilemmas (Hervey, 2007; Constable et al., 2011). Cottone (2001) agrees that the reflection process is not one of the mind, but an appraisal process of actions and a continued process of seeking alternative perspectives. Cottone (2001) encourages clinicians to go beyond the perspectives of supervisors, peers, and respected colleagues, and consider the cultural context in which the decision was implemented and how it affects the community at large.

For one, extending an open conversation to the patient in an effort to understand how the final decision affected them can increase feelings of safety and empathy for both the patient and counselor, especially if the ethical decision was contrary to the stated desire of that patient. Furthermore, I also suggest reaching out to community members and persons who identify within that associated culture. Shah (2011), described inviting pushback, where a group of people express resistance or redirection, as a way to 
show care and feelings of importance to the perspectives of underserved communities that may otherwise go unnoticed. Shah (2011) also brings attention to the fact that mistakes are inevitable during ethical decision-making, and it is essential that counselors prepare themselves for this kind of feedback. If not, the fear of criticism will keep counselors oblivious to the needs of patients, community members, and different cultures, therefore creating greater barriers that could potentially aid in the progression of mental healthcare for those in need.

\section{Embodiment of Step Nine}

In my movement reflection, I discovered that I was able to remove the heaviness of my culture from my back and place it in my hands in front of me. I now saw it as a tangible construct, something I could work with and move through. My body felt mobile with free flow as I integrated movements from the previous steps as a way to reflect on my experiences. There was a sense of gained knowledge and tools to assist me with navigating future complex ethical dilemmas in a culturally informed and embodied way.

By engaging in this in-depth exploration with the EEDM steps, I learned how meaningful this case was to me and possibly to underserved populations who engage in healthcare services. As opposed to intellectually escaping my bodily felt responses to the dilemma, these steps encouraged me to listen to and engage with them. Without doing so, I would not have reached the conclusions I have presented in this article. My connection to this clinical case was a deep visceral experience that had been silenced by an oppressive healthcare system and me, but illuminated through an embodied process. Current healthcare practices disempower and affect the long-term health of people of color because they are expected to comply with mono-cultural views of mental health and treatment. I made a decision to share Juan's spiritual experiences with his nurse against his will. My therapeutic approach of displaying respect and giving prominence to Juan's culturally based meaningmaking of his spiritual experience was what encouraged Juan to return to treatment. Still, it is essential to examine potential harmful outcomes and how they can be prevented or diminished until healthcare systems modify their operations.

\section{Discussion}

Throughout the ethical dilemma, I was the intermediary between my patient, the psychiatric nurse, and my site supervisor. ACA's (2014) Code of Ethics assert a collaborative process between counselors and patients, yet, in most ethical dilemmas, the counselor makes decisions in isolation (Birrell \& Bruns, 2016). Most clinical guidelines similarly recommend involving patients in decisions regarding assessment and treatment thus supporting collaborative and informed goals (Elwyn et al., 2006). This type of patient-centered care has been increasingly adopted as interdisciplinary teams realize how valuable shared decision-making (SDM) is for patient success and well-being (Adisso et al., 2018; Chewning et al., 2012; Elwyn, Edwards, Kinnersley, 1999; Elwyn, Edwards, Kinnersley, Grol, 2000; Légaré et al., 2011). 
Persons directly involved in an ethical dilemma have great potential to effectively influence the decision-making process, and no one voice should be given exclusive privilege over another (Birrell \& Bruns, 2016). From an RCT perspective, interconnection during ethical decision-making processes can invite real change in a positive direction for not only the patient, but for the counselor and institution as well.

RCT acknowledges that growth-fostering relationships, relationships that include increased understanding and empathy for one another's thoughts and feelings, display respect for the multitude of sociocultural aspects that each individual brings to the experience (Duffey \& Somody, 2011). As humans, we are wired to move through and toward connection with others, and it is the connection and relational experience that contributes to healthy functioning and flourishing (McCauley, 2013).

What I desired most during my ethical decision-making process was to have all the people involved in the dilemma to be in one room listening to each other with openness, curiosity, and empathy. I was the intermediary of all communication amongst my supervisors, Juan, and the nurse. It was exhausting relaying information, and a lot of the time I was repeating the same information to a different person. So much of my time and energy was expelled in this back and forth communication, only to implement the decision alone. As the intermediary, I additionally witnessed statements from my encounters with each of them that made me feel uncomfortable or suggested a lack of empathy for one another. I wished they were able to learn of one another's circumstances to create more understanding and empathy within the case. I understood that our workloads prevented a collaborative decision-making meeting that would have included my site supervisor, the nurse, Juan, and myself in one room discussing the details of the case and all the possible solutions to working with Juan's spiritual experience. I further understood that such a meeting would have been quite frightening for Juan who wanted to keep his experience a secret. I wondered how that might have been different if Juan discovered the hospital altered their policies to accept and consider his meaning making of his spiritual experience? A joint meeting could have saved me much time, energy, and stress over a dilemma that affected others and me deeply.

Based on my experiences with this ethical dilemma, I developed a model for active multicultural diversity (AMD), a term credited to Carmichael (2012), as a guide for ethical decision-making aimed at increasing effective outcomes for patients by taking culture from a concept that exists in one's awareness to a concept acted upon (Fig. 1). It incorporates the EEDM steps with SDM and the three M's of RCT: movement to mutuality, mutual empathy, and mutual empowerment. With the embodied ethical decision making steps at the center of decision-making, I encourage the patient, therapist, and treatment team to equally collaborate when making ethical decisions. In this way, the burden of resolving the ethical dilemma is not placed in the hands of one person, but instead, all are responsible for reaching a conclusion, therefore increasing the vitality of each person through involvement and interconnectedness. 


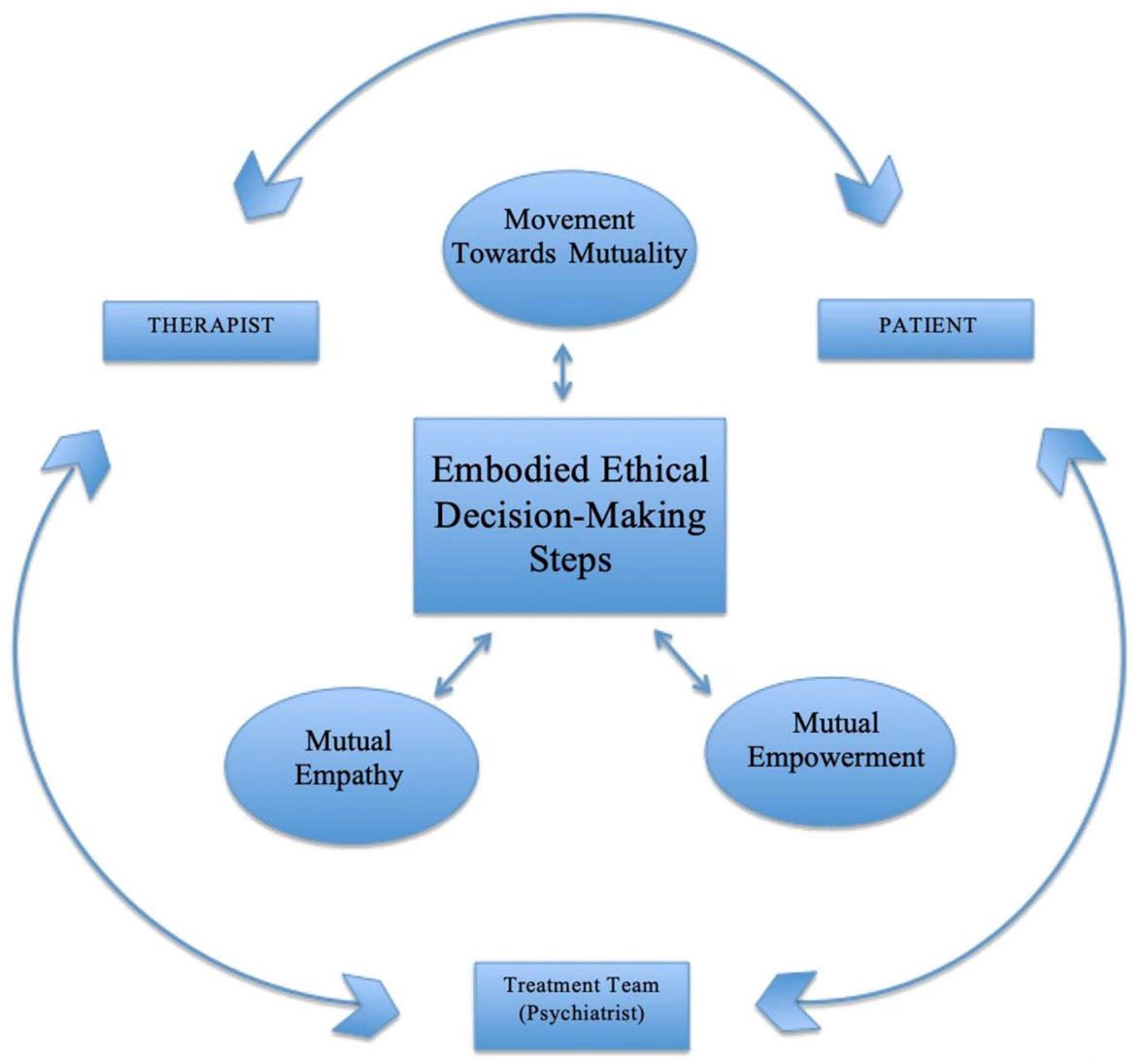

Fig. 1 Active multicultural diversity in ethical decision-making

\section{Movement Towards Mutuality}

Hartling and Miller (2004) describe non-mutual relationships as dominate/subordinate or power-over relationships, which the more powerful or dominant participant in the relationship receives greater benefit. Instead, movement towards mutuality calls for all participants of the relationship to engage in, and take emotional and cognitive action towards change (Hartling \& Miller, 2004). This movement towards mutuality benefits people by preventing humiliation while supporting growth, healing, and human rights. All participants in the ethical dilemma must be willing to change where possible and appropriate in order to see each other as equal individuals while collaborating to resolve the ethical dilemma. 


\section{Mutual Empathy}

Mutual empathy is the ability to be impactful and to be impacted in the relationship through seeing and feeling within the experience (Duffey \& Somody, 2011). It is through acceptance and validation that an authentic relationship can be built and become a priority (Duffey \& Somody, 2011; Hartling \& Miller, 2004). This is an essential piece to navigating complex ethical dilemmas.

\section{Mutual Empowerment}

Empowerment is the feeling of having control and understanding over one's life (World Health Organization, 2010). The World Health Organization (2010) realizes that institutions have a responsibility of operating in ways that empower the people and communities they serve to encourage vitality, health and well-being. Empowerment in relationships must be mutual so that all parties feel competent, heard, seen and respected as they collectively shape and develop the experience (Hartling \& Miller 2004). Decision-making is best done when those engaging in the collaborative process do so feeling confident and empowered.

I envision healthcare facilities employing a designated ethical dilemma consultant, to mediate the collaboration process. Clinicians, nurses, doctors, and even patients could send the consultant a notification that a potential ethical dilemma arose. From there, the consultant would initiate communication for all involved in the dilemma to decide on a date and time to meet and work through the AMD model to resolve the case. The consultation session could be structured according to the persons participating in the meeting. A session may involve a lot of movement or minimal movement with mostly postures and gestures. A simplified version might employ mindfulness techniques to identify body-felt sensations to each embodied step. The three M's should be illustrated at the beginning of each consultation to help clarify the intent and goal of engaging in the EEDM process. The three M's, movement to mutuality, mutual empathy, and mutual empowerment, effectively work to create an open and safe atmosphere that encourages full participation in the EEDM steps.

\section{Active Multicultural Diversity for Juan's Case}

In order for AMD to work in this clinical case with Juan, increased funding for mental health programs leading to less overworked professionals is a definite necessity. Professionals at the hospital were consistently double booked with patients for the majority of the workday. The oppressive system in which the hospital was situated, affected patients and employees alike. The hospital consistently treated people of color with limited support service options. It is feasible that if the hospital had sufficient funding for mental health services, increasing staff and office space, the AMD model could have been implemented in this clinical case. Further, to participate in a collaborative process, the patient, nurse, and clinical supervisor would have to be willing to engage with one another with an increased open mind and 
non-judgmental attitude. This would help cultivate a collaborative process insofar as Juan would have been able to communicate his desires to resolving the dilemma in a way that would also increase his trust for the hospital setting through our relational experience.

\section{Limitations and Possibilities}

Active multicultural diversity in ethical decision-making does not come without its challenges and limitations when considering the integral components of how westernized healthcare systems have been operating for decades. For one, SDM requires more time for collective consultations between healthcare professionals and patients (Elwyn et al., 1999). Most healthcare professionals are occupied with required treatment planning, writing notes, other consultations, case management, and other daily tasks. Counselors may also experience the obligation to educate patients on mental health to increase competency levels for ethical decision-making, which also requires more time (Elwyn et al., 1999). In light of this, patient decision aids, new technologies designed to prepare patients and to increase their knowledge of information related to treatment, are used to assist in making informed choices when collaborating with healthcare providers (Elwyn et al., 2006; Adisso et al., 2018). In an effort to increase active multicultural diversity in healthcare settings, patient decision aids should be made accessible to all communities, all populations, and in all forms of healthcare. Another limitation of active multicultural diversity is the perceived threat to power in professional-patient relationships (Elwyn et al., 1999). This is associated with a lack of cultural competence, caring knowledge, mono-cultural embedded lenses, and power-over preferences from health professionals and institutions. Moreover, just like cultural competency training is deficient in mental health programs, SDM is also deficient in programs and skill building workshops, and is further absent in modeling from older, more experienced clinicians (Elwyn et al., 1999). It is possible that with an ethical decision-making consultant on site, regular trainings could be provided to keep professionals and patients informed on ethical decision-making and cultural competency.

Finally, embodiment is a skill that dance/movement therapists and other bodybased practitioners are accustomed to, and it could be a challenging to engage non-body-based practitioners and patients in movement during an ethical decisionmaking process without significant willingness or training. This could reshape healthcare systems requiring leadership figures to provide more resources, education/training, and time to healthcare professionals so they are prepared and available to engage patients and team members in active multicultural diversity for ethical decision-making.

I can embrace the AMD model moving forward by including my patients in the EEDM process as a part of our therapy sessions, if a dilemma happens to emerge during our work together. We could collaborate to identify options to resolve the dilemma. I would then present those options in consultations with the treatment team to include and discuss their viewpoints. Another possibility is having someone from the treatment team join one of the therapy sessions with my patient and have 
them witness our movement, as identified in step six of sharing the dilemma. After, we might engage in a discussion to decide on an action to take, invite the team member to join the movement, or both. In this manner, there is an inclusion of multiple voices to collectively resolve a dilemma in an embodied way. Inviting a treatment team member into a session also indicates movement towards mutuality as each person shows initiative by taking time out of their day to dedicate to the safety and care of the patient. Mutual empathy happens in the process of moving and witnessing movement; illuminating how the movement affected each person in the room can deepen the process. Mutual empowerment is experienced in the feelings of inclusion, displaying respect and interest in one another's opinion.

\section{Conclusion}

The purpose of this clinical case study was to illustrate how the EEDM steps influenced ethical decision-making when cultural differences conflicted. I found that by engaging in the embodied ethical steps, I was able to deepen the decision-making process by accessing the lived experience of the dilemma in my body. I carried the heaviness of a silenced cultural identity until it was able to speak through movement. The ethical dilemma in this case was respect for culturally based meanings in treatment and how we name pathology. Culture is inadequately considered in healthcare operations, treatment models, and educational programs. We must actively consider how this deficiency affects patient health over time and disempowers underserved populations from engaging in treatment. The EEDM steps provide an effective way for working with diverse populations as we can connect to our bodies to explore new possibilities for complex situations. In this clinical case with Juan, though the decision to inform his nurse practitioner of his spiritual experience was against his will, our relationship encouraged his continued engagement with treatment services. To consider culturally based meanings in treatment, the relational experience is essential in order to receive support from different perspectives. Sharing the embodied decision-making process can be most effective for culturally situated ethical dilemmas. As suggested in the AMD model presented here, engaging in the EEDM steps through a RCT lens benefits silenced and underserved patients, and healthcare professionals with an increased sense of mutuality through a meaningful process.

\section{Compliance with Ethical Standards}

Conflict of interest: The author declares no conflict of interest.

Ethical Approval The author declares that all applicable ethics were taken into consideration.

Open Access This article is licensed under a Creative Commons Attribution 4.0 International License, which permits use, sharing, adaptation, distribution and reproduction in any medium or format, as long as you give appropriate credit to the original author(s) and the source, provide a link to the Creative Commons licence, and indicate if changes were made. The images or other third party material in this article are included in the article's Creative Commons licence, unless indicated otherwise in a credit line to the 
material. If material is not included in the article's Creative Commons licence and your intended use is not permitted by statutory regulation or exceeds the permitted use, you will need to obtain permission directly from the copyright holder. To view a copy of this licence, visit http://creativecommons.org/licen ses/by/4.0/.

\section{References}

Adisso, E. L., Borde, V., Saint-Hilaire, M., Robitaille, H., Archambault, P., Cameron, C., Blais, J., ... Zomahoun, H. T. V. (2018). Can patients be trained to expect shared decision making in clinical consultations? Feasibility study of a public library program to raise patient awareness. PLoS ONE, 13(12). https://doi.org/10.1371/journal.pone.0208449

Allmon, A. L. (2013). Religion and the DSM: From pathology to possibilities. Journal of Religion and Health, 52, 538-549. https://doi.org/10.1007/s10943-011-9505-5

Alqahtani, M. M. J., \& Altamimi, N. (2015). Code of ethics and professionalism in light of cultural competency: A guideline for Saudi psychologists, supervisors, and trainees. Psychological Studies, 61(2), 103-112. https://doi.org/10.1007/s12646-016-0354-X

American Counseling Association. (2014). ACA code of ethics. Retrieved from https://www.counseling .org/docs/ethics/2014-aca-code-of-ethics.pdf

American Dance Therapy Association. (2015). The code of ethics and standards of the American dance therapy association (ADTA) and the dance/movement therapy certification board (DMTCB). Retrieved from https://adta.org/wp-content/uploads/2015/12/Code-of-the-ADTA-DMTCB-Final.pdf

American Dance Therapy Association. (2014). What is dance/movement therapy? Retrieved from https:// adta.org/2014/11/08/what-is-dancemovement-therapy/

American Psychiatric Association. (2013). Diagnostic and statistical manual of mental disorders (5th ed.). Washington, DC: Author.

Anderson, E. (1994). The code of the streets. The Atlantic. Retrieved from https://www.theatlantic.com/ magazine/archive/1994/05/the-code-of-the-streets/306601/; p. 1-19

Ayala, J. F. (2010). The difference of being human: Morality. National Academy of Sciences (US), 4. Retrieved from https://www.ncbi.nlm.nih.gov/books/NBK210003/\#ddd00220

Birrell, P. J., \& Burns, C. M. (2016). Ethics and relationship: From risk management to relational engagement. Journal of Counseling and Development, 94, 391-397. https://doi.org/10.1002/ jcad. 12097

Bradley, E., \& Green, D. (2018). Involved, inputting or informing: "Shared" decision making in adult mental health care. Health Expectations, 21, 192-200. https://doi.org/10.1111/hex.12601

Carmichael, N. G. (2012). Turning towards multicultural diversity competence in dance/movement therapy. American Journal of Dance Therapy, 34, 99-113. https://doi.org/10.1007/s1046 5-012-9140-Z

Chewning, B., Bylund, C., Shah, B., Arora, N., Gueguen, J. A., \& Makoul, G. (2012). Patient preferences for shared decisions: A systemic review. Patient Education Counseling, 86(1), 9-18. https:// doi.org/10.1016/j.pec.2011.02.004

Chicago Community Trust. (2018). In north Lawndale, health challenges begin at birth. Retrieved from https://cct.org/2018/02/in-north-lawndale-health-challenges-begin-at-birth/

Chmielewski, C. (2004). Values and culture in ethical decision making. NACADA Clearinghouse of Academic Advising Resources. Retrieved from https://www.nacada.ksu.edu/Resources/Clearinghouse/ View-Articles/Values-and-culture-in-ethical-decision-making.aspx

Christine, P. J., \& Kaldjian, L. C. (2013). Communicating evidence in shared decision making. American Medical Association Journal of Ethics, 13(5), e0196839.

Constable, E. G., Kreider, T. B., Smith, T. F., \& Taylor, Z. R. (2011). The confidentiality of a confession: A counseling intern's ethical dilemma. Retrieved from https://counselingoutfitters.com/vistas/vista s11/Article_37.pdf

Cottone, R. R. (2001). A social constructivism model of ethical decision making in counseling. Journal of Counseling and Development, 79, 39-45.

Csordas, T. J. (1993). Somatic modes of attention. Cultural Anthropology, 8(2), 135-156. 
Dominiquez, M. L. (2017). LGBTQIA people of color: Utilizing the cultural psychology model as a guide for the mental health assessment and treatment of patients with diverse identities. Journal of Gay \& Lesbian Mental Health, 21(3), 203-220.

Duffey, T., \& Somody, C. (2011). The role of relational-cultural theory in mental health counseling. Journal of mental health counseling, 33(3), 223-242.

Elwyn, G., Edwards, A., \& Kinnersley, P. (1999). Shared decision-making in primary care: The neglected second half of the consultation. British Journal General Practice., 49(443), 477-482.

Elwyn, G., Edwards, A., Kinnersley, P., \& Grol, R. (2000). Shared decision making and the concept of equipoise: The competences of involving patients in healthcare choices. British Journal General Practice, 50(460), 892-899.

Elwyn, G., O’Connor, A., Stacey, D., Volk, R., , Edwards, A., Coulter, A., ... Whelan, T. (2006). Developing a quality criteria framework for patient decision aids: Online international Delphi consensus process. British Medical Journal Publishing Group. https://doi.org/10.1136/bmj.38926.629329.AE

Estrada, D. (2005). Multicultural conversations in supervision: The impact of the supervisor's racial/ethnic background. Guidance and Counseling, 21(1).

Evans, A. M., Levitt, D. H., \& Henning, S. (2012). The application of ethical decision-making and selfawareness in the counselor education classroom. Journal of Counselor Preparation and Supervision, 4(2), 41-52.

Frame, M. W., \& Williams, C. B. (2005). A model of ethical decision making from a multicultural perspective. Counseling and Values, 59, 165-179.

Gauthier, J., Pettifor, J., \& Ferrero, A. (2010). The universal declaration of ethical principles for psychologists: A culture-sensitive model for creating and reviewing a code of ethics. Ethics and behavior, 20(3-4), 179-196. https://doi.org/10.1080/10508421003798885

Giordano, A. L., \& Cashwell, C. S. (2014). Entering the sacred: Using motivational interviewing to address spirituality in counseling. Counseling and Values, 59, 65-79. https://doi.org/10.1002/ j.2161-007X.2014.00042.x

Goldman, E. (2004). As others see us: Body movement and the art of successful communication. New York: Routledge.

Hardy, K. (2015). Speaking out against learned voicelessness [Blog post]. Retrieved from https://www. psychotherapynetworker.org/blog/details/686/a-black-therapist-in-america

Harris, D. A. (2016). The ADTA's first half-century: Ma(r)king history with an eye to the horizon. American Journal of Dance Therapy., 38, 259-267. https://doi.org/10.1007/s10465-016-9232-2

Hartling, L. M., \& Miller, 37J. B. (2004). Creating new relational possibilities, creating change. Retrieved from https://www.humuliationstudies.org/documents/hartling/HartlingExcerptMutuality.pdf

Hebenstreit, H. (2017). The national association of social workers code of ethics and cultural competence: What does Anna Fadiman's the spirit catches you and you fall down teach us today? Health and Social Work, 42(2), 103-107. https://doi.org/10.1093/hsw/hlx007

Herlitz, A., Munthe, C., Törner, M., \& Forsander, G. (2016). The counseling, self-care, adherence approach to person-centered care and shared decision making: Moral psychology, executive autonomy, and ethics in multi-dimensional care decisions. Health Communication, 31(8), 964-973.

Hernández, P. (2003). The cultural context model in supervision: An illustration. Journal of Feminist Family Therapy. https://doi.org/10.1300/J086v15n04_01

Hervey, L. (2007). Embodied ethical decision making. American Journal of Dance Therapy, 29(2), 91-108. https://doi.org/10.1007/s10465-007-9036-5

Hoose, W. H. V. (1986). Ethical principles in counseling. Journal of Counseling And Development, 65, $168-169$.

Ivers, N. N., Rogers, J. L., Borders, L. D., \& Turner, A. (2017). Using interpersonal process recall in clinical supervision to enhance supervisees' multicultural awareness. The Clinical Supervisor, 36(2), 282-303.

Jennings, L., Sovereign, A., Bottorff, N., Mussell, M. P., \& Vye, C. (2005). Nine ethical values of master therapists. Journal of Mental Health Counseling, 27(1), 32-47.

Jernigan, M. M., Green, C. E., Helms, J. E., \& Perez-Gualdron, L. (2016). An examination of people of color supervision dyads: Racial identity matters as much as race. Training and Education in Professional Psychology, 4(1), 62-73. https://doi.org/10.1037/a0018110

Kitchener, K. S. (1984). Intuition, critical evaluation and ethical principles: The foundation for ethical decisions in counseling psychology. The Counseling Psychologist, 12(3), 43-55.

Laws, T., \& Chilton, J. A. (2013). Ethics, cultural competence, and the changing face of America. Pastoral Psychology, 62, 175-188. https://doi.org/10.1007/s11089-012-0428-1 
Légaré, F., Stacey, D., Gagnon, S., Dunn, S., Pluye, P., Frosch, D., ... Graham, I. D. (2011). Validating a conceptual model for an inter-professional approach to shared decision making: A mixed methods study. Journal of Evaluation in Clinical Practice, 17(4), 554-564.

McCauley, M. (2013). Relational-cultural theory: Fostering healthy coexistence through a relational lens. Retrieved from https://www.beyondintractability.org/essay/relational-cultural-theory

McEldowney, R., \& Connor, M. J. (2011). Cultural safety as an ethic of care: A praxiological process. Journal of Transcultural Nursing, 22(4), 342-349. https://doi.org/10.1177/1043659611414139

Miller, H. F., \& Davis, T. E. (2016) Practitioner's guide to ethical decision making. [Journal article]. Retrieved from https://www.counseling.org/docs/default-source/ethics/practioner-39-s-guide-toethical-decision-making.pdf?sfvrsn $=10$

Moore, C. L. (2014). Meaning in motion: Introducing laban movement analysis. Devnver, CO: MoveScape Center.

Oramas, J. E. (2017). Counseling ethics: Overview of challenges, responsibilities, and recommended practices. Journal of Multidisciplinary Research, 9(3), 47-58.

Ratts, M. J., \& Hutchins, A. M. (2009). ACA advocacy competencies: Social justice advocacy at the client/student level. Journal of Counseling and Development, 87, 269-275.

Robson, M., Cook, P., Hunt, K., \& Alred, G. (2000). Towards ethical decision-making in counselling research. British Journal of Guidance \& Counselling. https://doi.org/10.1080/03069880020004730

Schmidsberger, F., \& Löffler-Stastka, H. (2018). Empathy is proprioceptive: The bodily fundament of empathy-A philosophical contribution to medical education. BioMed Central Medical Education. https://doi.org/10.1186/s12909-018-1161-y

Schwartz, A. (2018, July 31). Somatic psychology and the satisfaction cycle [Blog post]. Retrieved from https://drarielleschwartz.com/somatic-psychology-satisfaction-cycle-dr-arielle-schwartz/\#.XW7oA pNKgnU

Shah, S. A. (2012). Ethical standards for transnational mental health and psychosocial support (MHPSS): Do no harm, preventing cross-cultural errors and inviting pushback. Clinical Social Work Journal, 48, 438-449. https://doi.org/10.1007/s10615-011-0348-z

Sieck, Winston. (2019, September 26). Cultural norms: Do they matter? [Blog post]. Retrieved from https ://www.globalcognition.org/cultural-norms/\#targetText=Cultural\%20norms\%20are\%20the\%20sta ndards, growing\%20up $\% 20$ in $\% 20 \mathrm{a} \% 20$ society.

Smith, S. L. (2012). The effects of race and cultures on ethical decision-making (Unpublished master's thesis). Columbia College Chicago, Chicago, IL.

Timimi, S. (2014). No more psychiatric labels: Why formal psychiatric diagnostic systems should be abolished. International Journal of Clinical and Health Psychology, 14, 208-215.

Tortora, S. (2006). The dancing dialogue. Baltimore, MD: Paul H. Brookes Publishing Co.

Trahan, D. P., \& Lemberger, M. E. (2014). Critical race theory as a decisional framework for the ethical counseling of African American clients. Counseling and Values, 59, 112-124. https://doi. org/10.1002/j.2161-007X.2014.00045.X

Vereen, L. G., Hill, N. R., \& McNeal, D. T. (2008). Perceptions of multicultural counseling competency: Integration of the curricular and the practical. Journal of Mental Health Counseling, 30(3), 226-236.

Wade, M. E. (2015). Handling conflicts of personal values. Ethics Inquiries. Retrieved from https:// www.counseling.org/docs/default-source/ethics/ethics-columns/ethics_april_2015_personal-value s.pdf?sfvrsn=1e24522c_4

Wadley, J. (2016). The struggle is real. Voices The Art \& Science of Psychotherapy, 52(3), 91-94.

Walker, K., Burman, E., \& Gowrisunkur, J. (2002). Counting black sheep: Contextualizing therapeutic relations. Psychodynamic Practice, 8(1), 55-73. https://doi.org/10.1080/13533330110119303

Welfel, E. R. (2001). Ethics in counseling and psychotherapy: Standards, research and emerging issues. Belmont, CA: Wadsworth.

Welfel, E. R. (2016). Ethics in counseling and psychotherapy: Standards, research, and emerging issues (6th ed.). Boston, MA: Cengage Learning.

World Health Organization. (2010). User empowerment in mental health. Retrieved from https://www. euro.who.int/_data/assets/pdf_file/0020/113834/E93430.pdf

Zheng, P., \& Gray, M. (2014). Influence of culture on ethical decision making in psychology. Ethics and Behavior, 24(6), 510-522. https://doi.org/10.1080/10508422.2014.89107546 
Publisher's Note Springer Nature remains neutral with regard to jurisdictional claims in published maps and institutional affiliations.

Megz Roberts, MA, R-DMT, is a graduate from Columbia College Chicago with an MA in Dance/Movement Therapy and Counseling. Currently, Megz works as a primary sex and relationship therapist with individuals, partners, and the LGBTQIA + community at a private practice in Chicago, IL. Megz actively practices the Active Multicultural Diversity model in their work with clients and community members every day. Megz has discovered that building mutual, power-sharing relationships and establishing crosscultural empathy are key factors to healing and moving towards needed change in the world.

\section{Affiliations}

\section{Megz Roberts ${ }^{1}$}

$\triangle \quad$ Megz Roberts

Megroberts18@yahoo.com

1 Columbia College Chicago, Chicago, IL, USA 